\title{
Micas, Metamorphism and Critical Element Enrichment
}

Barbara E. KunZ ${ }^{1}$, Clare. J. WARREN ${ }^{1}$, Nigel B.W. HARRIS $^{1}$, TOM. W. ARGLES ${ }^{1}$, FRANCES E. JENNER ${ }^{1}$

${ }^{1}$ School of Environment, Earth and Ecosystem Sciences, The Open University, Milton Keynes MK7 6AA, UK;

barbara.kunz@open.ac.uk

The process(es) involved in critical metal (e.g. $\mathrm{Li}, \mathrm{Cs}, \mathrm{Ta}, \mathrm{Sn} \& \mathrm{~W})$ enrichment in granitic magmas has long been a matter of discussion: fractional crystallisation from typical parental magmas is incapable of producing the observed enrichment on its own. Potential alternative enrichment processes include prograde metamorphism, partial melting and assimilation of pre-enriched protoliths. Currently unknown is the relative importance of any enrichment in the original protolith versus the concentrating potential of sub- and supra-solidus metamorphic reactions. Comprehensive concentration datasets of elements of economic interest in different metamorphic minerals are also currently lacking. We present the first large-scale dataset of in-situ LA-ICP-MS trace-element data of $\mathrm{Li}, \mathrm{Cs}$, Ta, Sn \& W in metapelitehosted muscovite and biotite from three different metamorphic cross-sections covering sub-greenschist to granulite-facies conditions. Our data show distinctive concentration changes during metamorphism that are seemingly independent of geological/tectonic setting (continental collision vs. crustal thinning). Our dataset confirms the previously predicted pre-enrichment potential of metamorphic reactions and the importance of studying such processes to constrain the formation of crust-sourced critical metal deposits. 